\title{
Antecedents of Consumer Attitude towards Blogger Recommendations and its Impact on Purchase Intention
}

\author{
Phang Ing @ Grace* and Ting Ming
}

\begin{abstract}
Manuscript type: Research paper.

Research aims: This study aims to fill in the literature gap by examining the relationship between various antecedent factors affecting consumer attitude towards blogger recommendations and their purchase intention.

Design/ Methodology/ Approach: A total of 384 questionnaires were collected and analysed using the partial least squares (PLS) approach.

Research findings: The results highlight the relationships existing between consumer attitude and the antecedent factors namely, perceived usefulness, trustworthiness, information quality and perceived benefits. The study also confirms the mediation role of consumer attitude towards blogger recommendations. Most importantly, consumer attitude towards blogger recommendations is found to have significant influence on consumer purchase intention.

Theoretical contributions/ Originality: This study provides a comprehensive empirical examination of the antecedent factors that contribute to consumer attitude towards blogger recommendations, previously examined by different researchers in separate studies. It is found that trustworthiness is the main factor contributing to consumer attitude towards blogger recommendations, followed by information quality, perceived usefulness and perceived benefits. Attitude towards blogger recommendations is found to have a strong
\end{abstract}

\footnotetext{
* Corresponding author: Phang Ing @ Grace is a Senior Lecturer at the Faculty of Business, Economics and Accountancy, Universiti Malaysia Sabah, Jalan UMS, 88400 Kota Kinabalu, Malaysia. Email: gracep@ums.edu.my

Ting Ming is an Operations Executive at Tokio Marine Life Insurance Malaysia Berhad, Block A-3A-G, KK Times Square, Signature Office, Off Coastal Highway, 88100 Kota Kinabalu, Sabah, Malaysia. Email: tingming@tokiomarinelife.com.my
} 
impact on purchase intention; it also serves as a mediator between the antecedent factors and purchase intention.

Practitioner/ Policy implications: This study provides useful evidence which support the influential power of blogs as a type of effective integrated marketing tool. The findings also recommend some evaluation criteria for choosing and evaluating the effectiveness of blogger recommendations that influence consumer attitude and purchase intention. Overall, blogger recommendations have to be perceived as useful, trustworthy and carry good quality information before consumers can be influenced.

Research limitation: This study is constrained by limitations such as blog types and variables. Future research could be extended to include more diverse blog types, more contributing variables on attitude and a bigger geographical coverage.

Keywords: Blogger Recommendations, Consumer Attitudes, Information Quality, Purchase Intention, Trustworthiness.

JEL Classification: M31

\section{Introduction}

With a total of 18 million active users and a penetration rate of 59 per cent, social media in Malaysia enjoyed an encouraging seven per cent growth rate in the year 2016 (Kemp, 2016). As a popular platform for interactions, social media in Malaysia has managed to bridge millions of users across the globe with similar hobbies, interests as well as views (Ioanas \& Stoica, 2014). Such social media platforms include blogs, MySpace, YouTube and Facebook (Sin, Nor, \& Al-Agaga, 2012).

Blogs are popular social media platforms for recording and discussing personal feelings, ideas, and opinions related to particular events in one's daily life (Hsu, Lin, \& Chiang, 2013) and it is especially popular among bloggers themselves, readers, and marketers (Colliander \& Dahlen, 2011; Schertler, Kreunen, \& Brinkmann, 2014). The popularity and potential of a blogger's recommendation is evident and the underlying logic is simple: consumers trust another consumer's comments more than those given by product/service companies (Lu, Chang, \& Chang, 2014). This is more so especially if the comments are made by those who are perceived to be experts.

Previously, bloggers depend on their individual or private blogs to share comments on products or services. Today, the scenario is slightly different. Many of them now link and make themselves available not 
only through their private blogs but also on other social media platforms such as Facebook and Instagram. Users of these blogs and social media platforms have various purposes with some even becoming popular with a list of followings (e.g., well-known bloggers like Grace Bonney). They become celebrities; some bloggers are reported to have as many as 250 million social media followers. These celebrity social influencers earn millions of dollars for endorsement programmes and other businesses generated offline such as product lines and book deals (O'Connor, 2017). Their goal is to create electronic word of mouth (eWOM) via blogs (Brown, Barry, Dacin, \& Gunst, 2005; Osman, Yearwood, \& Vamplew, 2009) so as to reap financial benefits. Without doubt, a blogger's opinion and recommendation can affect consumer purchase intention (Colliander \& Dahlen, 2011; Halvorsen, Hoffmann, CosteManiere, \& Stankeviciute, 2013; Erkan \& Evans, 2016). Therefore, who the consumers select as a suitable and effective blogger is a matter of crucial importance to the marketers as consumers are informed of the latest news and information via blogs that they frequently visit (Sin et al., 2012).

Despite the popularity of social media and the vast amount of research done on eWOM (Kim \& Ko, 2012; Ioanas \& Stoica, 2014; Hajli, 2014; Erkan \& Evans, 2016), few studies have focused on blogs and bloggers' recommendations and its impact on consumer attitude and purchase intention (Hsu et al., 2013). In one study, Halvorsen et al. (2013) interviewed Norwegian consumers' buying behaviours on a particular blog type i.e., fashion blog. Based on their study, it is concluded that fashion blogs do indeed affect consumer behaviours. In the Asian Pacific context, marketing researchers frequently manipulate variables such as blog types and product constructs to assess a blog's advertising effectiveness (Ho, Chiu, Chen, \& Papazafeiropoulou, 2015) or the influence of personality traits i.e., need for cognition and susceptibility to eWOM (Morimoto \& Trimble, 2012). Only a handful of studies (Hsu et al., 2013; Lu et al., 2014; Hanifati, 2015) have attempted to examine how consumer attitude and purchase intention are influenced by bloggers' recommendations, particularly in the Asian context. These studies do not have separate assessments for blogger recommendations and the blog's recommendations which include comments from peer consumers (Wu \& Lee, 2012; Lee \& Ma, 2012; Casaló, Flavián, \& Guinalíu, 2011). Hence, it is difficult for marketers to differentiate the effectiveness between bloggers' recommendations and peer consumers' recommendations on consumer 
attitudes and purchase intentions. Taking into account the significant amount of money marketers have spent on blogger endorsements and sponsorship, an examination using separate assessment tools to detect the difference between bloggers' recommendations and peer consumers' recommendations is necessary.

Several researchers have examined the antecedents affecting consumer attitude and purchase intention on online shopping. Among these studies, Al-Debei, Akroush and Ashouri (2015) examined how perceived benefits and trust can affect consumer attitude towards online shopping in Jordan. However, no focus was given to any specific media type or purchase intention. From the Taiwanese perspective, Hsu et al. (2013) examined consumer attitude towards online shopping by manipulating factors such as perceived usefulness and trust towards blogger recommendations. Focussing on the Indonesian market, Hanifati's (2015) study confirmed the impact of food blogger's perceived usefulness on Indonesian consumer attitude and behaviours in choosing a restaurant. Erkan and Evans (2016) thus posited that information quality is important for an online shopping context because consumers approach products and services more eagerly when the information satisfies their demands. Meanwhile, Lee and Ma (2012) examined how perceived benefits play an important role in shaping consumer attitude towards online reviews. From the outcomes noted of these studies, it can be deduced that such studies had examined online shopping or online reviews only. They had not comprehensively tested these variables in the context of blogger recommendations.

As argued by Hsu et al. (2013), different countries have different lifestyles and culture. The adoption of information technology (IT) related products is also culturally bound (Leidner \& Kayworth, 2006). A social media study by Imran, Han, and Akhter (2016) found culture as the critical influencing factor affecting the number of shares and comments noted on social media platforms. Most importantly, the impact and intensity varied across different cultures. Yap and Gaur (2016), in their paper on social networking usage, also asserted that findings cannot be generalised because regions are culturally different. Therefore, findings retrieved from the Taiwanese context (where blogs are a popular social media type) or the Western context may not be applicable on a multiracial, multireligion and multicultural society like Malaysia and in particular, the state of Sabah where blogs are still building their existence. Of the studies that had focussed on the Malaysian context, most samples were also from Peninsular Malaysia 
markets (Shojaee \& Azman, 2013; Al-Rahmi \& Othman, 2013) with very little focus paid to the less developed market of Sabah. Thus, there exists a gap in terms of user profiles and backgrounds.

Sabah is among one of the poorest states of Malaysia. Despite its status, consumers in Sabah were found to spend 75 per cent more time shopping online when compared to consumers in Peninsular Malaysia (Bernama, 2017). Bernama reported that the findings can be attributed to the longer hours spent online due to the recent significant improvement in logistics and payment gateways. However, published data pertaining to social media usage in Sabah, particularly on blogs, are still lacking. This makes it difficult to assess the market potential of blogger's recommendations in influencing Sabah consumers' online shopping behaviour in the context of Sabah.

To present a robust examination of the blogging scenario of Sabah, this study extends Hsu et al.'s (2013) study by incorporating additional factors which have been extracted from the studies of AlDebei et al. (2015), Erkan and Evans (2016), and Lee and Ma (2012). These additional factors include perceived usefulness, trustworthiness, perceived benefits and information quality. This study also aims to examine the relationship existing between consumer attitude toward blogger recommendations and purchase intention. It further looks at the mediating role of attitudes by applying the partial least squares (PLS) approach in assessing the structural fit of the framework tested.

This paper is divided into five sections. Section 1 presents the introduction to this study. Section 2 reviews the literature of past studies and hypotheses development. Section 3 details the methodology used in the study. Section 4 reports the results while Section 5 discusses the findings and implications of the research.

\section{Literature Review and Hypotheses Development}

A person's behaviour is influenced by his/her intention or willingness to try and the amount of effort he/she is willing to contribute in order to carry out the behaviour (Ajzen, 1991). This is well explained by the theory of reasoned action (TRA) (Fishbein \& Ajzen, 1975) and the theory of planned behaviour (TPB) (Ajzen, 1991). This means the stronger the individual's intention to carry out a behaviour, the higher the tendency of that behaviour to be performed. Relevant to this is the behaviour of purchase intention which is a vital concept in marketing (Morrison, 1979). Wu and Lee (2012) and Morwitz (2012) proposed that purchase 
intention is a good predictor of actual buying behaviour. It is the main input for predicting future sales as well as for impacting marketing actions on purchase behaviours (Morwitz, 2012). A number of marketing researchers (Lu et al., 2014) have examined and defined purchase intention as the willingness of consumers to buy a certain product/ service at a particular time and within a particular circumstance.

The advancement of technology and market uncertainty (Zamri \& Idris, 2013) however, have caused the study of purchase intention to become more sophisticated and critical when compared to the past (Madahi \& Sukati, 2012). Taking the context of blogging, for instance, purchase intention refers to the extent to which a blog reader believes the blogger's recommendation could improve his/her knowledge regarding a product/service (Hsu et al., 2013). This belief can eventually influence his/her attitude and behaviour. As mentioned earlier, even though reports noting the power of social media and the huge influence of blog sites and bloggers are vast, empirical studies focussing on blogger recommendations are still lacking. In addition to this, the examination of antecedent factors affecting consumer attitude leading to purchase intention too has not been addressed.

The TRA and technology acceptance model (TAM) (Venkatesh \& Davis, 2000) explain that individuals form beliefs by referring to the information or the normative practices of a group or peers (Hsu et al., 2013). In a buying situation, consumers frequently refer to the opinions of reference groups for their purchase (Brown \& Reingen, 1987), especially for expensive, unfamiliar or high involvement products. This is used by the consumers to assess how useful those products can be, in other words, the perceived usefulness of such products. It is also used by marketers to predict user acceptance of information technology (Hsu et al., 2013). In the case of blogging, perceived usefulness refers to the usefulness of the blogger's recommendation in improving consumers' buying performance (Erkan \& Evans, 2016). Bloggers who are perceived as experts in a particular product category are viewed as persons who are neutral and non-commercial (Hsu et al., 2013). Thus, their opinions and recommendations are viewed to be more reliable and useful (Wu, 2011), especially in the context of online shopping where face to face encounters do not happen. Casaló et al. (2011) studied perceived usefulness as an antecedent to favourable attitude towards reviews from an online travel community. Their research presented some significant results. Hsu et al. (2013) also examined how bloggers' recommendations of product usefulness and consumers' trusting beliefs can influence 
consumer attitudes and their behavioural intentions towards online shopping. They too found a significant positive impact of usefulness on attitude. The study by Hanifati (2015) showed a similar result whereby perceived usefulness significantly influenced consumers' behavioural intention. In general, literature shows that consumers form favourable attitudes when the recommendation is perceived to be useful. Based on this, it is hypothesised that:

$\mathrm{H}_{1}$ : Perceived usefulness positively influences consumer attitude towards blogger recommendations.

Spread by mainly word of mouth (WOM), blogs are found to be a credible source of information when compared to other media sources (Hsu et al., 2013). In the context of blogs, information is sent and received through marketing techniques such as commercials and advertisements (Halvorsen et al., 2013). The basic element affecting consumers' willingness to accept a message in traditional WOM is trustworthiness and source credibility (Filieri, Alguezaui, \& Mcleay, 2015). Trustworthiness refers to the trust that viewers have towards the products recommended by the blogger (Wu \& Lee, 2012) while source credibility is the perception of a just, trustable, true or even accurate information (Lu et al., 2014). Trust is crucial in the online environment (Hsu et al., 2013) due to various associated environmental risks. In an online shopping environment, consumers tend to seek product information from different sources such as reference groups and personal social media (e.g., blogs) so as to reduce the transaction risks (Hsiao, Lin, Wang, Lu, \& Yu, 2010). Famous bloggers tend to attract bigger numbers of loyal readers as these bloggers display a high level of trustworthiness ( $\mathrm{Wu} \&$ Lee, 2012); and they are often viewed as non-commercial entities (Hsu et al., 2013). In other words, they are mostly users of a particular product/service and upon their own use, they make recommendations to other users. Sparks, Perkins, and Buckley (2013) studied attitude and purchase intention of travellers staying at a resort. They postulated that the trustworthiness of online reviews had significantly affected the attitude and purchase intention of the travellers. Consumer-generated reviews for specific contents are viewed to be more trustworthy than manager-generated contents. This is because consumer reviews carry very specific information that fulfills the need of the consumers. The two-way communication between bloggers and readers can eventually increase perceptions of trust. This is especially true when the positive reviews come from bloggers who 
are perceived to be experts in their field rather than mere consumers (Plotkina \& Munzel, 2016) or marketers. Based on this it is thus hypothesised that:

\section{$\mathrm{H}_{2}$ : Trustworthiness positively influences consumer attitude towards blogger recommendations.}

Besides trustworthiness on bloggers and perceived usefulness of products, consumers can be further persuaded to show higher purchase intention in another way. Park, Lee, \& Han (2007) suggested that if the good quality reviews are high in number, consumers tend to show higher purchase intention. This finding is consistent with Zhang, Zhao, Cheung, and Lee (2014). Reviews which are informative will act as complementary information that reduces perceived risks thereby improving purchase intention. Information quality is defined as "the bloggers' general perception of the collective content quality of blogs in a specific blog service provider" (Wang \& Lin, 2011, p. 52). Consumers perceive information characteristics such as relevance, understandability, sufficiency, objectivity and adequacy persuasiveness as important criteria for judging content quality (Park et al., 2007; Zhang et al., 2014). The advancement of online technology allows consumers to use and rely heavily on consumer-generated media to obtain valuable consumer reviews (Filieri et al., 2015). Hence, the quality of the information, especially those provided by the expert blogger, is crucial in forming favourable attitudes. Based on this, it is thus hypothesised that:

$\mathrm{H}_{3}$ : Information quality positively influences consumer attitude towards blogger recommendations.

Consumers receive both positive and negative reviews (i.e. benefits versus costs) from blogs. They try to use these reviews to maximise their benefits over costs (Lee \& Ma, 2012). In the case of bloggings, perceived benefits refer to consumers' beliefs about the relative advantages of using a recommendation post. Consumers form favourable attitudes when they perceive from online reviews that they would enjoy more benefits than costs. The perception of the positive outcomes arising from a particular option or perceived benefit (Leung, 2013) drives their purchase intention (Park et al., 2007). Despite its importance, consumers' perceived benefits of online reviews including blogger reviews, have not been explicitly studied (Lee \& Ma, 2012). In the case of blogger recommendations, the relative advantages from using a recommendation post refers to the perceived usefulness of the review 
in helping them to gather information about the features, functions, price range, quality, and popularity of the product (Lee \& Ma, 2012). Hence, consumers form more favourable attitudes towards blogger recommendations when the perceived benefits are high. Based on this, it is thus hypothesised that:

$\mathrm{H}_{4}$ : Perceived benefits positively influences consumer attitude towards blogger recommendations.

Attitude towards an object in an online shopping context is defined as "a collected set of beliefs individuals form regarding a particular object and it can not only predict the willingness of consumers to perform an action but also mediate the influence of beliefs formed as a result of online informational cues on purchase intention" (Sparks et al., 2013, p. 2). As defined by Hanifati (2015, p. 150), "attitude towards blogger recommendations is the extent to which a blog reader has positive feelings about the information provided by the blogger". Consumer attitude has been widely used as the prediction of consumer behaviour (Casaló et al., 2011). Well known theories such as TRA, TPB and TAM have proposed that the individuals' behaviour intentions are influenced by their attitude towards the behaviour. For instance, Prendergast, Ko and Yuen (2010) found that the positive attitude towards an online forum strengthen the purchase intention of the products discussed. In the case of online product recommendations, Hsiao et al. (2010) also posited that attitude towards online shopping is the most important predictor of a user's behavioural intention. In other words, increased positive attitude will lead to increased behavioural intention. A study on young social media users' beliefs, attitude, and behavioural responses toward social media advertising also found a significant relationship between attitude toward social media advertising and behavioural responses (Chu, Kamal, \& Kim, 2013). A positive attitude towards social media advertising can lead to a higher involvement in brand messages and information seeking efforts and eventually, the purchase intention. Therefore, a more favourable attitude towards blogger's recommendations will lead to a higher purchase intention. Thus, it is hypothesised that:

$\mathrm{H}_{5}$ : Consumer attitude towards blogger recommendations positively influences consumer purchase intention.

Sparks et al. (2013) noted the mediation role of attitude in the relationships of different variables. In their study, attitude towards 
staying at a resort is found to mediate the influence of beliefs about the utility of the reviews and trust on purchase intention. This finding suggests that trust in a resort and the reviews together with the beliefs of consumers in the utility of the reviews, influence consumer attitude toward staying at the resort. This, in turn, mediates the effect of such belief on purchase intention. A similar result is found in Liang, Ekinci, Occhiocupo and Whyatt's (2013) study. Here, travellers' overall attitude towards the eWOM communication mediates the direct influence of the antecedents of travellers' eWOM communication (namely, subjective norms, adoption of the electronic communication media technology and customer dissatisfaction/satisfaction with travel consumption experiences) on the travellers' intention to use eWOM communication media. Similarly, in the case of blogger recommendation, attitude serves as a mediator between the four antecedent factors and purchase intention. Based on this, it is thus hypothesised that:

$\mathrm{H}_{6}$ : Consumer attitude towards blogger recommendations mediates the relationship between perceived usefulness and purchase intention.

$\mathrm{H}_{7}$ : Consumer attitude towards blogger recommendations mediates the relationship between trustworthiness and purchase intention.

$\mathrm{H}_{8}$ : Consumer attitude towards blogger recommendations mediates the relationship between information quality and purchase intention.

$\mathrm{H}_{9}$ : Consumer attitude towards blogger recommendations mediates the relationship between perceived benefits and purchase intention.

\section{Research Methodology}

Earlier methodological considerations include blog types and respondent criteria. In this study, two pretests were carried out prior to the main study. Pretest 1 aims to determine the types of blogs that were frequently visited by the respondents. Respondents were instructed to answer the questionnaire based on their experiences with the blog sites that they frequently visit. From a total of 30 responses collected, it appears that fashion blogs ( 36.7 per cent) and travel blogs ( 40 per cent) were the highest rated in terms of frequency of visit. These two blog types were then used as a general reference for blog types in the main study. 
Pretest 2 aims to cross check the reliability and testability of the questionnaire used in the main study. Due to the bilingual nature of the questionnaire (English and Malay), it is important to identify and eliminate potential problems such as translation differences in meaning, typo errors and formatting issues. Back to back translation, which is commonly used in marketing research (Douglas \& Craig, 2007) was carried out. Following the questionnaire, a total of 10 respondents were interviewed so that their feedback can be used to improve the comprehensiveness of the questionnaire. Every measurement item and sentence in the questionnaire was thoroughly checked by both the interviewees and interviewers. Any discrepancy was resolved through mutual agreement after discussion.

To ensure respondents' relevancy, a screening question was asked prior to the answering of the questionnaire: "Have you read articles in a blog?" All constructs and items in the questionnaire were adopted and adapted from extant literature with modifications made to suit this study (refer to Appendix A for the list of measurement items). The fivepoint scale items for perceived usefulness were adopted from Hsu et al. (2013). The nine 5-point scale items for trustworthiness were adopted from Hsu et al. (2013), Lee and Ma (2012) and Erkan and Evans (2016). For information quality, six 5-point scale items were developed from Park et al. (2007). One item, "each recommendation post of the products is objective" was later deleted from the structural testing due to its low factor loading. The seven 5-point scale items of perceived benefits were adapted from Lee and Ma (2012). Meanwhile, the four 5-point scale items for attitude toward blogger's recommendations were adopted from Casaló et al. (2011) and Lee, Xiong and Hu (2012). Finally, the four 5 -point scale items for purchase intention were adopted from Plotkina and Munzel (2016).

The target population of this study was the people who have read blog articles, particularly those residing in the districts of Kota Kinabalu, Tawau and Sandakan in the Sabah state. These three districts have the highest population number (Department of Statistics Malaysia, 2010) as well as a higher number of Internet users. From the sum of population (total population of the three districts $=1,284,394$ people), the sample size of 384 was calculated by adopting the convenience sampling method, with the sampling fraction of 0.03 per cent over the total population. In addition, the $\mathrm{G}^{*}$ Power analysis with the effect size of 0.15 (Cohen, 1988) was run to determine the minimum required sample size. A total number of 384 valid responses were collected for the main study 
out of 400 questionnaires distributed (response rate of 96 per cent). This figure exceeds the minimum requirement of 138 and therefore, is considered as appropriate and acceptable for analysis.

\section{Data Analysis and Findings}

\subsection{Respondent Profile}

The profile of the respondents is shown in Table 1, showing the majority being Malays and Bumiputera (77.6 per cent), females (59.9 per cent), aged between 26-35 years old (41.1 per cent) and with minimum qualification of bachelor's degree (37.8 per cent). The ethnic composition of the respondents was found to be representative of the Sabahan population. From the screening question procedure, more female blog

Table 1: Profile of Respondents

\begin{tabular}{llrr}
\hline $\begin{array}{l}\text { Demographic } \\
\text { Variables }\end{array}$ & Categories & Frequency & $\begin{array}{r}\text { Percentage } \\
(\%)\end{array}$ \\
\hline Age & S18 years & 62 & 16.1 \\
& 19-25 years & 131 & 34.1 \\
& 26-35 years & 158 & 41.1 \\
& $\geq 46$ years & 28 & 7.3 \\
& Male & 5 & 1.4 \\
\hline Gender & Female & 154 & 40.1 \\
& Malay and Bumiputera & 230 & 59.9 \\
\hline Ethnic & Sabah and Sarawak & 298 & 77.6 \\
& Chinese & 76 & 19.8 \\
& Indian & 10 & 2.6 \\
\hline Education Level & SPM & 81 & 21.0 \\
& STPM/Certificate/Diploma & 77 & 20.2 \\
& Bachelor's degree & 145 & 37.8 \\
& Master's and above & 81 & 21.0 \\
\hline Frequently Visited & Fashion & 132 & 34.4 \\
Blog Type & Travel & 148 & 38.5 \\
& Others (food, games and toys, & 104 & 27.1 \\
& car accessories; novels and & & \\
& eBooks, etc.) & & \\
\hline
\end{tabular}


viewers/readers were identified. Similar to the results of the pre-test 1 , respondents indicate that they frequently visited blogs such as fashion and travel blogs (34.4 per cent and 38.5 per cent respectively) while the rest (27.1 per cent) visited blogs related to food, games and toys, cars and accessories as well as novels and eBooks.

\subsection{Common Method Bias}

Common method bias is caused by the variance in the responses due to adopted measurements rather than the respondents (Brannick, Chan, Conway, Lance, \& Spector, 2010). Since this study employed a crosssectional survey, common method bias may be a concern in affecting study results. Therefore, Harman's single factor test was carried out; and the extracted sum of squared loading for the first variable is 30.52 per cent, which is lower than the cutoff point of 50 per cent (Podsakoff, MacKenzie, Lee, \& Podsakoff, 2003). This implies that the data did not suffer from common method variance.

\subsection{Analysis of Measurement Model}

Structural equation modeling with PLS approach was used to analyse the measurement and structural models. This study adopted a twostep procedure recommended by Anderson and Gerbing (1988). In this approach, the measurement model was first examined to measure reliability, convergent validity and discriminant validity. Following this, the structural model was formed to test the hypotheses.

Table 2 shows the consistency, reliability and convergent validity of the measurement model that was constructed in this study. All the loadings in the study exceeded the recommended threshold value of 0.5 (Hair, Black, Babin, \& Anderson, 2010). They also ranged from 0.656 to 0.861 . The average variance extracted (AVE) of the constructs ranged from 0.517 to 0.659 which also exceeded the recommended threshold value of 0.5 . These results prove the adequate convergence validity of the constructed measurement model. The composite reliability (CR) values ranged from 0.845 to 0.911 which also exceeded the recommended threshold value of 0.7 . This indicates a good reliability.

The square root of every AVE value of each latent construct was calculated so as to reflect the discriminant validity. It can be seen from Table 3 that the square root of the AVE at the diagonals was found to exceed the off diagonals element in the corresponding row and column. 
Table 2: Internal Consistency Reliability and Convergent Validity

\begin{tabular}{|c|c|c|c|c|}
\hline & Items & Factor Loadings & AVE & CR \\
\hline \multirow[t]{5}{*}{ Perceived Usefulness } & PU1 & 0.763 & 0.600 & 0.883 \\
\hline & PU2 & 0.814 & & \\
\hline & PU3 & 0.699 & & \\
\hline & PU4 & 0.786 & & \\
\hline & PU5 & 0.806 & & \\
\hline \multirow[t]{9}{*}{ Trustworthiness } & TR1 & 0.692 & 0.517 & 0.906 \\
\hline & TR2 & 0.731 & & \\
\hline & TR3 & 0.747 & & \\
\hline & TR4 & 0.736 & & \\
\hline & TR5 & 0.656 & & \\
\hline & TR6 & 0.701 & & \\
\hline & TR7 & 0.709 & & \\
\hline & TR8 & 0.768 & & \\
\hline & TR9 & 0.725 & & \\
\hline \multirow[t]{5}{*}{ Information Quality } & IQ1 & 0.707 & 0.521 & 0.845 \\
\hline & IQ3 & 0.712 & & \\
\hline & IQ4 & 0.719 & & \\
\hline & IQ5 & 0.775 & & \\
\hline & IQ6 & 0.694 & & \\
\hline \multirow[t]{7}{*}{ Perceived Benefits } & PB1 & 0.741 & 0.595 & 0.911 \\
\hline & PB2 & 0.792 & & \\
\hline & PB3 & 0.799 & & \\
\hline & PB4 & 0.780 & & \\
\hline & PB5 & 0.776 & & \\
\hline & PB6 & 0.798 & & \\
\hline & PB7 & 0.707 & & \\
\hline \multirow{4}{*}{$\begin{array}{l}\text { Attitude towards } \\
\text { Blogger Recommendations }\end{array}$} & ATT1 & 0.805 & 0.659 & 0.885 \\
\hline & ATT2 & 0.813 & & \\
\hline & ATT3 & 0.825 & & \\
\hline & ATT4 & 0.804 & & \\
\hline \multirow[t]{4}{*}{ Purchase Intention } & PI1 & 0.756 & 0.627 & 0.870 \\
\hline & PI2 & 0.720 & & \\
\hline & PI3 & 0.823 & & \\
\hline & PI4 & 0.861 & & \\
\hline
\end{tabular}

Note: $\mathrm{AVE}=$ average variance extracted, $\mathrm{CR}=$ composite reliability. 
Table 3: Discriminant Validity

\begin{tabular}{lcccccccr}
\hline & Mean & SD & ATT & IQ & PB & PU & PI & TR \\
\hline ATT & 3.82 & 0.648 & $\mathbf{0 . 8 1 2}$ & & & & & \\
IQ & 3.41 & 0.590 & 0.605 & $\mathbf{0 . 7 2 2}$ & & & & \\
PB & 3.55 & 0.548 & 0.538 & 0.517 & $\mathbf{0 . 7 7 1}$ & & & \\
PU & 3.94 & 0.561 & 0.557 & 0.462 & 0.624 & $\mathbf{0 . 7 7 5}$ & & \\
PI & 3.72 & 0.563 & 0.692 & 0.550 & 0.449 & 0.482 & $\mathbf{0 . 7 9 2}$ & \\
TR & 3.63 & 0.620 & 0.615 & 0.709 & 0.432 & 0.485 & 0.567 & $\mathbf{0 . 7 1 9}$ \\
\hline
\end{tabular}

Note: Diagonals represent the square root of the AVE while the off diagonals represent the correlations. ATT $=$ Attitude towards Blogger Recom-mendation, $\mathrm{IQ}=$ Information Quality, $\mathrm{PB}=$ Perceived Benefits, $\mathrm{PU}=$ Perceived Usefulness, $\mathrm{PI}=$ Purchased Intention, $\mathrm{TR}=$ Trustworthiness.

Bolded figures in Table 3 display the square roots of the AVE while the non-bolded figures are the inter-correlation values between the constructs.

\subsection{Structural Model Analysis and Hypotheses Testing}

A 5000 resample of bootstrapping procedure was run in order to test the structural model and its associated hypotheses. As indicated in Figure 1 , the $R^{2}$ values of the dependent variable (purchase intention) and the mediating variable (attitude towards bloggers' recommendations) are 0.479 and 0.516 , respectively. The $\mathrm{R}^{2}$ values were above the threshold of 0.333 , indicating a moderate model. Path coefficient was then used to examine the strength of the relationships. According to Hair et al. (2010), the value of path coefficient should be greater than 0.1 and is significant at 0.05 level. Figure 1 shows that all path coefficients are found to be larger than 0.1 and also significant at the 0.05 level.

Table 4 and Figure 1 show the results of the t-values after the bootstrapping procedure, indicating that $\mathrm{H}_{1}$ to $\mathrm{H}_{4}$ are supported. Perceived usefulness $(\beta=0.213, t$-value $=4.082, p<0.01)$, trustworthiness $(\beta=0.283$, $\mathrm{t}$-value=5.113, $p<0.01)$, information quality $(\beta=0.218, \mathrm{t}$-value $=4.017$, $p<0.01)$, and perceived benefits $(\beta=0.170, t$-value $=3.449, p<0.01)$ were found to have positive relationships with consumer attitudes towards blogger recommendations. Further, consumer attitudes towards blogger recommendations positively influenced consumer purchase intention towards products recommended by bloggers $(\beta=0.692$, $t$-value $=16.873$, $p<0.01)$, hence $\mathrm{H}_{5}$ is also supported. 


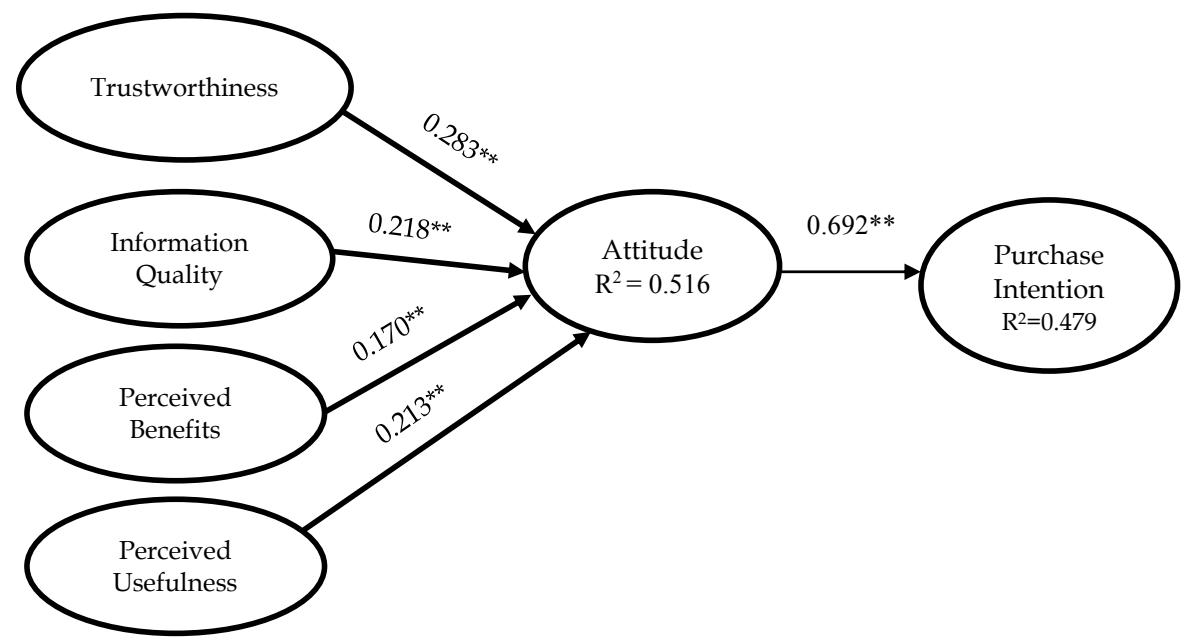

Figure 1: Structural Model Analysis

Table 4: Results of Hypothesis Testing

\begin{tabular}{ccccccc}
\hline Hypotheses & Relationship & $\begin{array}{c}\text { Std. } \\
\text { Beta }(\beta)\end{array}$ & $\begin{array}{c}\text { Std. } \\
\text { Error }\end{array}$ & t-value & $\mathrm{f}^{2}$ & Decision \\
\hline $\mathrm{H}_{1}$ & $\mathrm{PU} \rightarrow \mathrm{AT}$ & 0.213 & 0.052 & $4.082^{* *}$ & 0.052 & Supported \\
$\mathrm{H}_{2}$ & $\mathrm{TR} \rightarrow \mathrm{AT}$ & 0.283 & 0.055 & $5.113^{* *}$ & 0.077 & Supported \\
$\mathrm{H}_{3}$ & $\mathrm{IQ} \rightarrow \mathrm{AT}$ & 0.218 & 0.054 & $4.017^{* *}$ & 0.043 & Supported \\
$\mathrm{H}_{4}$ & $\mathrm{~PB} \rightarrow \mathrm{AT}$ & 0.170 & 0.049 & $3.449^{* *}$ & 0.032 & Supported \\
$\mathrm{H}_{5}$ & $\mathrm{AT} \rightarrow \mathrm{PI}$ & 0.692 & 0.041 & $16.873^{* *}$ & 0.918 & Supported
\end{tabular}

Note: $\mathrm{PU}=$ Perceived Usefulness, Trustworthiness $=\mathrm{TR}, \mathrm{IQ}=$ Information Quality, $\mathrm{PB}=$ Perceived Benefits, AT $=$ Attitude, $\mathrm{PI}=$ Purchase Intention. ${ }^{* *}$ denotes significance at $p<0.01$.

Further to the above, the effect size $\left(\mathrm{f}^{2}\right)$ of the relationships were tested and results are presented in Table 4 so as to evaluate the strength of the statistical claim. A larger absolute value generally indicates a stronger effect. According to Cohen (1988), $\mathrm{f}^{2}$ of 0.02 is considered small, 0.15 is considered medium, and 0.35 is considered large. In this study, the highest $\mathrm{f}^{2}$ was found in the relationship between consumer attitudes towards bloggers' recommendations and consumer purchase intention towards products recommended by bloggers, which is 0.918 . 
Meanwhile, the relationship between perceived benefits and consumer attitudes towards products recommended by bloggers had the lowest effect size, $\mathrm{f}^{2}=0.032$. Among the four antecedent factors, trustworthiness possessed the highest $\mathrm{f}^{2}$ of 0.077 , indicating that trustworthiness is the most important factor in influencing consumer attitudes toward blogger recommendations.

\subsection{Mediation Analysis}

A mediation test was carried out by bootstrapping the sampling distribution of the indirect effect (Hair, Hult, Ringle, \& Sarstedt, 2017) as suggested by Preacher and Hayes (2008) and Zhao, Lynch and Chen (2010). The mediation test procedure was based on Zhao et al.'s (2010) guidelines instead of Baron and Kenny's (1986). This is because "more recent research point to the conceptual and methodological problems of the approach" (Hair et al., 2017, p. 232). Structural equation model (SEM) approach is said to dominate the "causal steps approach" of Baron and Kenny (1986) as it did not assume the three equations in the three-variable-non-recursive causal model to be independent (Zhao et al., 2010). Baron and Kenny's (1986) golden standard of "full mediation" was argued to be less relevant in many empirical studies as majority of the studies were concluded with "partial mediation" or direct effect (Zhao et al., 2010). The independent variable does not have to significantly affect the dependent variables. In fact, the significant indirect effect is posited to be the only requirement for mediation, when using bootstrap test and not Sobel test (Zhao et al., 2010). Sobel test was also not included as it is not consistent with the non-parametric PLS-SEM method (Hair et al., 2017). The mediation test was done by bootstrapping the sampling distribution of the indirect effect. Bootstrapping is applicable to small sample size data without making assumptions on the shape of the variable distribution or the sampling distribution (Hair et al., 2017). According to Hair et al. (2017), "bootstrapping yields a higher level of statistical power when compared to the Sobel test" (p. 235). Mediation effects occur when the mediator intervenes between the exogenous and endogenous variables (Hair et al., 2017).

Table 5 shows that the mediation tests carried out supported all the mediation hypotheses. Attitude towards blogger's recommendation was found to be a significant mediator for the relationships between the four antecedent factors and purchase intention (Perceived Usefulness $\rightarrow$ 
Table 5: Mediation Test Results

\begin{tabular}{cccccccc}
\hline $\begin{array}{l}\text { Hypo- } \\
\text { theses }\end{array}$ & Relationships & $\begin{array}{c}\text { Std. } \\
\text { Beta }(\beta)\end{array}$ & $\begin{array}{c}\text { Std. } \\
\text { Error }\end{array}$ & $\begin{array}{c}\text { Lower } \\
\text { Limit }\end{array}$ & $\begin{array}{c}\text { Upper } \\
\text { Limit }\end{array}$ & t-Value & Results \\
\hline $\mathrm{H}_{6}$ & $\mathrm{PU} \rightarrow \mathrm{AT} \rightarrow \mathrm{PI}$ & 0.147 & 0.037 & 0.076 & 0.219 & $4.021^{* *}$ & Mediation \\
$\mathrm{H}_{7}$ & $\mathrm{TR} \rightarrow \mathrm{AT} \rightarrow \mathrm{PI}$ & 0.196 & 0.039 & 0.120 & 0.272 & $5.066^{* *}$ & Mediation \\
$\mathrm{H}_{8}$ & $\mathrm{IQ} \rightarrow \mathrm{AT} \rightarrow \mathrm{PI}$ & 0.151 & 0.039 & 0.075 & 0.227 & $3.902^{* *}$ & Mediation \\
$\mathrm{H}_{9}$ & $\mathrm{~PB} \rightarrow \mathrm{AT} \rightarrow \mathrm{PI}$ & 0.118 & 0.037 & 0.046 & 0.189 & $3.210^{* *}$ & Mediation \\
\hline
\end{tabular}

Note: $\mathrm{PU}=$ Perceived Usefulness, Trustworthiness $=\mathrm{TR}, \mathrm{IQ}=$ Information Quality, $\mathrm{PB}=$ Perceived Benefits, AT $=$ Attitude, PI $=$ Purchase Intention. ${ }^{* *}$ denotes significance at $p<0.01$.

Purchase Intention: $\beta=0.147, \mathrm{t}=4.021, p<0.01$; Trustworthiness $\rightarrow$ Purchase Intention: $\beta=0.196, \mathrm{t}=5.066, \quad p<0.01$; Information Quality $\rightarrow$ Purchase Intention: $\beta=0.151, t=.902, \quad p<0.01$ and finally, Perceived Benefits $\rightarrow$ Purchase Intention: $\beta=0.118, \mathrm{t}=3.210, p<0.01$ respectively). In other words, a change in perceived usefulness, trustworthiness, perceived benefits and information quality can lead to a change in attitude towards bloggers' recommendations which, in turn, changes the purchase intention. There is also no zero in between upper limit (UL) values and lower limit (LL) values thereby indicating the mediation effects. Thus, the mediation results support $\mathrm{H}_{6}, \mathrm{H}_{7}, \mathrm{H}_{8}$ and $\mathrm{H}_{9}$.

\section{Discussion and Implication}

On the relationship noted between the four antecedent factors and consumer attitude, this study finds that the factor of trustworthiness has the greatest impact, followed by information quality, perceived usefulness and perceived benefits. The relationship between trustworthiness and consumer attitude towards blogger recommendations is statistically supported in this study which shows that consumer attitude towards blogger recommendations tend to be more favourable if trust is involved. Trust helps consumers to avoid risks in the online context and the positive outcomes brought by trust will help to develop the positive attitude of consumers towards carrying out a behaviour (Casaló et al., 2011). The findings also show that blogs are viewed as credible sources of information (Hsu et al., 2013) and bloggers with high popularity can attract many loyal readers, thereby displaying the characteristic of trustworthiness (Wu \& Lee, 2012). In fact, consumer-generated reviews 
(in this case, the blogger recommendations) with specific contents are viewed to be more trustworthy than manager-generated contents and this seems to increase consumers' perceptions of trust (Sparks et al., 2013). These bloggers are also viewed as non-commercial entities (Hsu et al., 2013). The present findings are consistent with Zhang et al. (2014) in that reviews from a trustable blogger were perceived to be credible and more trustworthy than company sponsored advertising. They are also considered as true, accurate, convincing and reliable. Based on their firsthand experience and more neutral opinions, recommendations by a blogger who is viewed as an expert, can generate a higher degree of trust (Halvorsen et al., 2013). In fact, trustworthiness is the most important antecedent factor that can influence consumers' attitude towards blogger recommendations.

The findings of this study posit a positive relationship between information quality and consumer attitude towards blogger recommendations. Blogger recommendations will also act as a complementary information in improving consumers' purchase intention. Consumers' attitude towards blogger recommendations tend to be more favourable when the information quality is clear, credible, understandable and carries high quality reasons to support the opinions. These consumers use consumer-generated media to obtain reviews from previous customers whom they perceive to be valuable. Consumers rely on these reviews heavily as they are highly valued information which is not biased and is based on personal experience (Filieri et al., 2015). The comments could be negative or positive in nature and are considered as important for consumers' decision making. Therefore, consumers are better persuaded; they also become more inclined towards buying the product (Park et al., 2007).

The findings of this study indicate that consumers form favourable attitude towards bloggers' recommendations which are perceived to be useful. This finding is aligned with Hsu et al.'s (2013) study which investigated the influence of the usefulness of blogger recommendations and consumers' trusting beliefs on their purchase intention toward online shopping. The reason for this could be the influence bloggers' recommendations have on consumers' buying process. This serves as a vital source of information for the consumers during the searching stage and it can finally help consumers to affirm their final purchase decision. Undoubtedly, bloggers are considered as experts who are able to discuss the products in a realistic and unbiased manner. By providing useful information, their recommendations also help readers to form attitudes 
about the strength and weakness of certain products. Clearly, such recommendations help readers to improve their shopping effectiveness, performance, productivity and also their understanding of the products. This finding is consistent with Casaló et al.'s (2011) study which reveals that perceived usefulness of the online travel community reviews increase the efficiency of travellers in planning their travel plans.

The findings of this study also show a significant positive relationship between perceived benefits and consumer attitude towards blogger recommendations. This suggests that by being able to gather information about the products such as features, functions, price range, quality and popularity (Lee \& Ma, 2012), consumers also form favourable attitudes towards blogger recommendations. This helps to reduce their risks of making a decision. Lee and Ma (2012) investigated consumer perceptions of online consumer reviews and the effects of consumer perceptions on consumer attitude and usage behaviours. They proposed that perceived benefits contribute significantly to favourable attitudes toward online reviews which also support the outcome of this study. Thus, it can be inferred that consumers tend to have more favourable attitudes towards blogger recommendations when the perceived benefits of the blogger recommendations are higher.

This study examined the proposed structural relationships and the effect size of each of the relationships. The relationship between attitude toward bloggers' recommendations and purchase intention was found to have the largest effect size. This finding conforms to the findings of previous studies conducted by Prendergast et al. (2010), Hsiao et al. (2010), Chu et al. (2013) and Lu et al. (2014), with the exception that previous studies did not examine blogger recommendation effects specifically. Prendergast et al. (2010), for instance, argued that when consumers have positive attitudes towards an online forum, the forum communications will be perceived to be more persuasive. Therefore, this strengthens the purchase intention. The current study is also able to show that attitude is a very important factor affecting behavioural intention. The more consumers like the recommendations, the more consumers perceive the blogger recommendations to be good, positive and favourable, the more likely they will consider buying the recommended product.

The findings of the main study also support the outcome noted in the mediation role of consumer attitude towards blogger recommendations. Antecedent factors such as perceived usefulness, trustworthiness, information quality and perceived benefits influenced 
consumer attitude towards blogger recommendations which in turn mediates the effect on purchase intention. Sparks et al.'s (2013) found a significant mediation effect of attitude towards staying at a resort. Liang et al. (2013) found that travellers' overall attitude mediates the direct influence of subjective norms, adoption of electronic communication media technology and customer dissatisfaction and satisfaction with travel consumption experience on travellers' intention to use eWOM communication media. Undoubtedly, blogger recommendation is a popular type of eWOM that is frequently utilised by consumers. Likewise, this study also finds that consumer attitude towards blogger recommendations mediates the effect of blogger recommendations on consumer' intention to purchase. Rather than having direct influences, antecedent factors such as perceived usefulness, trustworthiness, information quality and perceived benefits have stronger indirect relationships with purchase intention.

The outcomes generated here will benefit academicians and marketing practitioners. This study has presented evidence to show how blogger recommendations can influence consumer attitude and behavioural intention structure. Previously, Hsu et al. (2013) only partially examined the role of perceived usefulness and trust on consumer attitude toward blogger recommendations while Erkan and Evans (2016) tested the influence of information quality of social media on purchase intention and Lee and Ma (2012) examined how perceived benefits play an important role in shaping consumer attitude towards online reviews. Their studies did not differentiate between blogger recommendations from peer consumer recommendations; these studies also did not apply all the variables/factors to assess consumer attitude on purchase intention. That gap is filled by the current study which has successfully examined and confirmed the mediating role of attitude in the relationship between antecedent factors to attitudes and purchase intention.

From the practical perspective, useful evidence can be drawn to confirm the influential power of the blog as an effective integrated marketing communication tool. Therefore, marketers should utilise blogger recommendations to help consumers to understand their products hence increase sales. A useful and detailed recommendation provided by a blogger, based on firsthand experience can create persuasive messages which can enhance consumer purchase intention. Consumers are interested to know how a product works. They also welcome other information such as price, place, after sales services and warranties provided by bloggers including product features. Since some bloggers 
are sharing as well as offering promotional information based on firsthand experience, regardless of product brands, it is important to address and compare the different options available in the market. This information will be perceived as beneficial to consumers in terms of helping them to reduce perceived risks (e.g., time, resource, effort and monetary risks). This can improve and enhance consumers' decision making. In general, the recommendations should contain quality information with sufficient supporting reasons which are also objective, understandable, credible and clear.

This study provides valuable insights to marketers in choosing and evaluating their sponsored bloggers. It is proven by the effect size analysis that even though all antecedents are significant contributors, trustworthiness emerges as the most important contributing factor to favourable attitudes, followed by information quality, perceived usefulness and perceived benefits. Spreading mostly through word of mouth (WOM), consumers perceive blogger recommendations as a trustable source for their buying evaluations as compared to other media sources (Hsu et al., 2013). Smart bloggers with high popularity tend to attract more visitors to view their page in a day, better than the biggest newspaper circulation even (Wu \& Lee, 2012). Thus, it is important for marketers to choose a blogger who is not only popular but also trustable in building favourable consumer attitudes which can eventually influence their purchase intention.

Nonetheless, marketers have to be cautious with the blogger's reputation. While useful, beneficial and quality recommendations will improve consumer attitude towards blogger recommendations which in turn enhance their purchase intention, the opposite is also true. In the case of tour operators, travel agencies or the Ministry of Tourism, consideration should be given in hiring only popular bloggers with good reputation to write about their product/service reviews. Similarly for fashion blogs, fashion bloggers should recommend useful information such as current fashion trends, latest fashion or product launch, price comparison, promotional campaigns and outlet locations to influence consumers' attitudes. Since trustworthiness is the main concern, marketers need to be extra cautious about not offending consumers who hold negative impressions of sponsored reviews. Too much bloggers' positive reviews can cause the sponsored reviews to be viewed as bias and misleading (Lu et al., 2014). This may be viewed as just "a form of online ads rather than consumer review of personal usage experience" (Lu et al., 2014, p. 259). 
The findings of this study also suggest that marketers should stress on the quality of the recommended information so that its perceived usefulness and perceived benefits can be detected by consumers. Nonetheless, marketers need to give caution to the issue of information overload which could hinder information search and increase uncertainty (Lee \& Ma, 2012; Park, Lee, \& Han, 2006). Information overload occurs when "the volume of information supply exceeds the capacity of an individual" thereby leading to "dysfunctional consequences such as stress and anxiety" ((Morwitz, 2012, p. 198). Blogger recommendations could range from simple recommendations to attribute-value information which require different levels of cognitive processing of contents. In other words, while providing useful, beneficial and quality information to consumers, bloggers need to be careful with the delivery method and the web page design so as to reduce information overload.

Unlike Facebook users who have been traced properly by various online research companies, database on blog users in Malaysia is still unavailable. Nevertheless, this study has shed light on the use of blogs in the Malaysian context and in particular Sabah, where blog usage is still largely unidentified (Department of Statistics Malaysia, 2016). The findings of the present study has indicated that fashion and travel blogs are the two most frequently visited sites but other blogs such as food, $3 \mathrm{C}$ products, games and toys, cars and accessories, and novels may also be in demand. Therefore, marketers can use these insights to plan their future marketing strategies.

\section{Conclusion, Limitation and Recommendation for Future Research}

This study has confirmed the relationships between the four antecedent factors, namely perceived usefulness, trustworthiness, perceived benefits and information quality and attitude toward blogger recommendations. This study also finds a significant relationship between attitude and purchase intention as well as the mediating role of attitude towards blogger's recommendations.

However, the results of this study need to be interpreted and considered with some limitations. The first limitation is the generalisability of the findings. Even though the findings of the study conform to that of previous studies, other factors could play a part in influencing consumer attitude towards blogger recommendations and purchase intention. Besides demographic variables, moderators such as 
culture, product characteristics (e.g., complexity of the product, level of product involvement) or user readiness (e.g., blog user vs. non blog user, product user vs. non-product user) could be examined for their effects on blogger recommendations and consumer purchase intention. Most importantly, the data were collected from only the state of Sabah, rather than the whole of Malaysia, hence it limits the generalisability of the findings. Thus, more Internet as well as social media related studies should be conducted to examine consumers' online buying intention and decision making processes via the new media platform.

To date, there is limited published data indicating the total number of blog users, social media users or Internet users according to each state and district in Malaysia. This makes it difficult to determine the exact type of social media when conducting studies. Moreover, even though the screening questions were added to ensure that respondents were familiar with the subject matter, the incompleteness of data restricts the possibility of drawing a more precise sample size from the total number of blog users. The current study was only able to guide the respondents to the most frequently visited blogs such as fashion and travel blogs and not others. Further, data collection was not able to differentiate the blog types hence the findings cannot be further generalised to all blogs. Future study could examine the influence of blog types on attitude and buying patterns. Future research could also focus on one particular type of blog instead of several blogs. Since consumers may have different consideration factors in forming attitude and behavioural intention for different product categories, future studies should consider comparing bloggers who use private blogs and those who use multiple platforms (e.g. combining private blogs with Facebook and Instagram) so as to examine their influence on consumers' attitude and purchase intention. Experimental studies comparing the impacts of blogger recommendations and peer consumer recommendations will also provide useful insights to marketers.

In conclusion, this study has specifically measured the effect of blogger recommendations (excluding the effect of peer consumer recommendation); it also confirms the proposition that blogger recommendations affect consumer attitudes and purchase intention. This study suggests that factors such as perceived usefulness, trustworthiness, information quality, and perceived benefits need to be given extra attention so as to build favourable consumers' attitudes. Consumers who have favourable attitudes towards blogger recommendations have higher purchase intention towards the products recommended by 
bloggers. Thus, blogger recommendations can serve as an effective and important marketing tool for marketers.

\section{References}

Ajzen, I. (1991). The theory of planned behavior. Organizational Behavior and Human Decision Processes, 50(2), 179-211. http://dx.doi.org/10.1016/07495978(91)90020-T

Al-Debei, M.M., Akroush, M.N., \& Ashouri, M.I. (2015). Consumer attitudes towards online shopping: The effects of trust, perceived benefits, and perceived web quality. Internet Research, 25(5), 707-733. http://dx.doi. org/10.1108/IntR-05-2014-0146

Al-Rahmi, W.M., \& Othman, M.S. (2013). The impact of social media use on academic performance among university students: A pilot study. Journal of Information Systems Research and Innovation, 4(12), 1-10.

Anderson, J.C., \& Gerbing, D.W. (1988). Structural equation modeling in practice: A review and recommended two-step approach. Psychological Bulletin, 103(3), 411-423.

Baron, R.M., \& Kenny, D.A. (1986). The moderator-mediator variable distinction in social psychological research: Conceptual, strategic, and statistical considerations. Journal of Personality and Social Psychology, 51(6), 1173-1182.

Bernama (2017, September 7). Sabah, Sarawak internet users spend more time on online shopping. Retrived from http://www.freemalaysiatoday.com/ category/nation/2017/09/07/ sabah-sarawak-internet-users-spend-moretime-on-online-shopping/

Brannick, M.T., Chan, D., Conway, J.M., Lance, C.E., \& Spector, P.E. (2010). What is method variance and how can we cope with it? A panel discussion. Organizational Research Methods, 13(3), 407-420. http://dx.doi. org/10.1177/1094428109360993

Brown, J.J., \& Reingen, P.H. (1987). Social ties and word-of-mouth referral behavior. Journal of Consumer Research, 14(3), 350-362.

Brown, T.J., Barry, T.E., Dacin, P.A., \& Gunst, R.F. (2005). Spreading the word: Investigating antecedents of consumers' positive word-ofmouth intentions and behaviors in a retailing context. Journal of the Academy of Marketing Science, 33(2), 123-138, http://dx.doi.org/10.1177/ 0092070304268417

Casaló, L.V., Flavián, C., \& Guinalíu, M. (2011). Understanding the intention to follow the advice obtained in an online travel community. Computers in Human Behavior, 27(2), 622-633. http://dx.doi.org/10.1016/j.chb.2010. 04.013

Chu, S.C., Kamal, S., \& Kim, Y. (2013). Understanding consumers' responses toward social media advertising and purchase intention toward luxury products. Journal of Global Fashion Marketing, 4(3), 158-174. http://dx.doi. org/10.1080/20932685.2013.790709 
Cohen, J. (1988). Statistical power analysis for the behavioral sciences (2nd ed.). Hillsdale, NJ: Lawrence Erlbaum Associates.

Colliander, J., \& Dahlen, M. (2011). Following the fashionable friend: The power of social media. Weighing publicity effectiveness of blogs versus online magazines. Journal of Advertising Research, 51(1), 313-320. http://dx.doi. org/10.2501/JAR-51-1-313-320

Department of Statistics Malaysia. (2010). Population and housing census of Malaysia. Population distribution and basic demographic characteristics 2010. Putrajaya: Author.

Department of Statistics Malaysia (2016). Sabah @ a glance. Putrajaya: Author.

Douglas, S.P., \& Craig, C.S. (2007). Collaborative and iterative translation: An alternative approach to back translation. Journal of International Marketing, 15(1), 30-43.

Erkan, I., \& Evans, C. (2016). The influence of eWOM in social media on consumers' purchase intentions: An extended approach to information adoption. Computers in Human Behavior, 61(August), 47-55. http://dx.doi. org/10.1016/j.chb.2016.03.003

Filieri, R., Alguezaui, S., \& Mcleay, F. (2015). Why do travelers trust TripAdvisor? Antecedents of trust towards consumer-generated media and its influence on recommendation adoption and word of mouth. Tourism Management, 51(December), 174-185. http:/ /dx.doi.org/10.1016/j. tourman. 2015.05.007

Fishbein, M., \& Ajzen, I. (1975). Belief, attitude, intention and behaviour: An introduction to theory and research. Reading, MA: Addison-Wesley.

Hair, J.F., Black, W.C., Babin, B.J., \& Anderson, R.E. (2010). Multivariate data analysis: A global perspective (7th ed.). New Jersey, USA: Pearson Prentice Hall.

Hair, J.F., Hult, G.T.M., Ringle, C.M., \& Sarstedt, M. (2017). A primer on partial least squares structural equation modeling (PLS-SEM) (2nd Ed.). Thousand Oaks, CA: Sage Publications.

Hajli, M.N. (2014). A study of the impact of social media on consumers. International Journal of Market Research, 56(3), 387-404. http://dx.doi.org/ 10.2501/IJMR-2014-025

Halvorsen, K., Hoffmann, J., Coste-Maniere, I., \& Stankeviciute, R. (2013). Can fashion blogs function as a marketing tool to influence consumer behavior? Evidence from Norway. Journal of Global Fashion Marketing, 4(3), 211-224. http:/ /dx.doi.org/10.1080/20932685.2013.790707

Hanifati, A.N. (2015). The impact of food blogger toward consumer's attitude and behavior in choosing restaurant. International Journal of Humanities and Management Services, 3(3), 149-154.

Ho, C.H., Chiu, K.H., Chen, H., \& Papazafeiropoulou, A. (2015). Can internet blogs be used as an effective advertising tool? The role of product blog type and brand awareness. Journal of Enterprise Information Management, 28(3), 346-362. http:/ / dx.doi.org/10.1108/JEIM-03-2014-0021 
Hsiao, K.L., Lin, J.C.C., Wang, X.Y., Lu, H.P., \& Yu, H. (2010). Antecedents and consequences of trust in online product recommendations: An empirical study in social shopping. Online Information Review, 34(6), 935-953. http:// dx.doi.org/10.1108/14684521011099414

Hsu, C.L., Lin, J.C.C., \& Chiang, H.S. (2013). The effects of blogger recommendations on customers' online shopping intentions. Internet Research, 23(1), 69-88. http://dx.doi.org/10.1108/10662241311295782

Imran K., Han, D.P., \& Akhter W. (2016). Does culture matter in effectiveness of social media marketing strategy? An investigation of brand fan pages. Aslib Journal of Information Management, 68(6), 694-715. http://dx.doi. org/10.1108/ AJIM-03-2016-0035

Ioanas, E., \& Stoica, I. (2014). Social media and its impact on comsumer behavior. International Journal of Economic Practices and Theories, 4(2), 295-303.

Kemp, S. (2016, January 27). News: Digital in 2016. Retrieved from http:// wearesocial.sg/blog/2016/01/digital-2016/

Kim, A.J., \& Ko, E. (2012). Do social media marketing activities enhance customer equity? An empirical study of luxury fashion brand. Journal of Business Research, 65(10), 1480-1486. http://dx.doi.org/10.1016/j.jbusres. 2011.10.014

Lee, H.H., \& Ma, Y.J. (2012). Consumer perceptions of online consumer product and service reviews: Focusing on information processing confidence and susceptibility to peer influence. Journal of Research in Interactive Marketing, 6(2), 110-132. http:/ / dx.doi.org/10.1108/17505931211265426

Lee, W., Xiong, L., \& Hu, C. (2012). The effect of Facebook users' arousal and valence on intention to go to the festival: Applying an extension of the technology acceptance model. International Journal of Hospitality Management, 31(3), 819-827. http:/ / dx.doi.org/10.1016/j.ijhm.2011.09.018

Leidner, D.E., \& Kayworth, T. (2006). A review of culture in information systems research: Toward a theory of information technology culture conflict. MIS Quarterly, 30(2), 357-399.

Leung, Y. (2013). Encyclopedia of behavioral medicine. In M.D. Gellman \& J.R. Turner (Eds.), Encyclopedia of Behavioral Medicine (pp. 1450-1451). New York, NY: Springer.

Liang, S.W.J., Ekinci, Y., Occhiocupo, N., \& Whyatt, G. (2013). Antecedents of travellers' electronic word-of-mouth communication. Journal of Marketing Management, 29(5-6), 584-606. http://dx.doi.org/10.1080/0267257X.2013. 771204

Lu, L.C., Chang, W.P., \& Chang, H.H. (2014). Consumer attitudes towards blogger's sponsored recommendations and purchase intention: The effect of sponsorship type, product type, and brand awareness. Computers in Human Behavior, 34(May), 258-266. http:/ / dx.doi.org/10.1016/j.chb.2014.02.007

Madahi, A., \& Sukati, I. (2012). The effect of external factors on purhcase intention amongst young generation in Malaysia. International Business Research, 5(8), 153-159. http:/ /dx.doi.org/10.5539/ibr.v5n8p153 
Morimoto, M., \& Trimble, C.S. (2012). Consumers' use of blogs as product information sources: From need-for-cognition perspective. The Marketing Management Journal, 22(2), 45-60.

Morrison, D.G. (1979). Purchase intentions and purchase behavior. Journal of Marketing, 43(2), 65-74.

Morwitz, V. (2012). Consumers' purchase intentions and their behavior. Foundations and Trends in Marketing, 7(3), 181-230. http://dx.doi/org/ $10.1561 / 1700000036$

O'Connor, C. (2017, April 10). Forbes top influencers: Meet the 30 power players making a fortune on social media. Retrieved from https://www/forbes.com/ sites/clareoconnor/2017/10/forbes-to-influencers-meet-the-30-powerplayers-making-a-fortune-on-social-media/\#5d3db84613c8

Osman, D., Yearwood, J., \& Vamplew, P. (2009). Weblogs for market research: Finding more relevant opinion documents using system fusion. Online Information Review, 33(5), 873-888. http://dx.doi.org/10.1108/ 14684520911001882

Park, D.H., Lee, J., \& Han, I. (2006). Information overload and its consequences in the context of online consumer reviews. Paper presented at the 10th Pacific Asia Conference on Information Systems (PACIS), Kuala Lumpur. Retrieved from www.pacis-net.org/file/2006/1096.pdf

Park, D.H., Lee, J., \& Han, I. (2007). The effect of on-line consumer reviews on consumer purchasing intentions: The moderating role of involvement. International Journal of Electronic Commerce, 11(4), 125-148. http://dx.doi. org/10.2753/JEC1086-4415110405

Plotkina, D., \& Munzel, A. (2016). Delight the experts, but never dissatisfy your customers! A multi-category study on the effects of online review source on intention to buy a new product. Journal of Retailing and Consumer Services, 29(March), 1-11. http:// dx.doi.org/10.1016/j.jretconser.2015.11.002

Podsakoff, P.M., MacKenzie, S.B., Lee, J.Y., \& Podsakoff, N.P. (2003). Common method biases in behavioral research: A critical review of the literature and recommended remedies. Journal of Applied Psychology, 88(5), 879-903. http://dx.doi.org/10.1037/0021-9010.88.5.879

Prendergast, G., Ko, D., \& Yuen, S.Y. (2010). Online word of mouth and consumer purchase intentions. International Journal of Advertising, 29(5), 687-708. http://dx.doi.org/10.2501/S0265048710201427

Preacher, K.J., \& Hayes, A.F. (2008). Contemporary approaches to assessing mediation in communication research. In A.F. Hayes, M.D. Slater, \& L.B. Snyder (Eds.), The Sage sourcebook of advanced data analysis methods for communication research (pp. 13-54). Thousand Oaks, CA: Sage Publications. http://dx. doi.org/10.4135/9781452272054.n2

Schertler, M., Kreunen, T., \& Brinkmann, A. (2014). Defining the role of fashion blogs: Have blogs redefined consumers' relationship with fashion brands or do they simply offer a new marketing tool for retailers? Arnhem: Crossmedia Lab in Utrecht en ArtEZ Hogeschoolvoor Kunsten. 
Sin, S.S., Nor, K.M., \& Al-Agaga, A.M. (2012). Factors affecting Malaysian young consumers' online purchase intention in social media websites. Procedia - Social and Behavioral Sciences, 40, 326-333. http://dx.doi.org/ 10.1016/j.sbspro.2012.03.195

Shojaee, S., \& Azman, A. (2013). An evaluation of factors affecting brand awareness in the context of social media in Malaysia. Asian Social Science, 9(17), 72-78. http:/ / dx.doi.org/10.5539/ass.v9n17p72

Sparks, B.A., Perkins, H.E., \& Buckley, R. (2013). Online travel reviews as persuasive communication: The effects of content type, source, and certification logos on consumer behavior. Tourism Management, 39(December), 1-9. http:/ /dx.doi.org/10.1016/j.tourman.2013.03.007

Venkatesh, V., \& Davis, F.D. (2000). A theoretical extension of the technology acceptance model: Four longitudinal field studies. Management Science, 46(2), 186-204. http:/ / dx.doi.org/10.1287/mnsc.46.2.186.11926

Yap, S.F., \& Gaur, S.S. (2016). Integrating functional, social, and psychological determinants to explain online social networking usage. Behaviour $\mathcal{E}$ Information Technology, 35(3), 166-183. http://dx.doi.org/10.1080/014492 9X.2015.1035336

Wang, S.M., \& Lin, J.C.C. (2011). The effect of social influence on bloggers' usage intention. Online Information Review, 35(1), 50-65. http://dx.doi. org/10.1108/14684521111113588

Wu, C.M. (2011). How quality influence user's continuance of the recommendation blog. Key Engineering Materials, 474-476, 1132-1136. http:// dx.doi.org/10.4028/www.scientific.net/KEM.474-476.1132

Wu, W.L., \& Lee, Y.C. (2012). The effect of blog trustworthiness, product attitude, and blog involvement on purchase intention. International Journal of Management and Information System, 16(3), 265-276. http://dx.doi.org/ 10.19030/ijmis.v16i3.7079

Zamri, N., \& Idris, I. (2013). The effects of attitude, social influnces and perceived behavioral control on intention to purhcase online shopping apparels in Malaysia: Case study on Zalora. Paper presented at the 3rd International Conference on Management, Penang. Retrieved from https://pdfs.semanticscholar. org/537a/f0345e07ca3c61be2d078c7c1786ad2adcd0.pdf

Zhang, K.Z.K., Zhao, S.J., Cheung, C.M.K., \& Lee, M.K.O. (2014). Examining the influence of online reviews on consumers' decision-making: A heuristicsystematic model. Decision Support Systems, 67(November), 78-89. http:// dx.doi.org/ 10.1016/j.dss.2014.08.005

Zhao, X., Lynch Jr, J.G., \& Chen, Q. (2010). Reconsidering Baron and Kenny: Myths and truths about mediation analysis. Journal of Consumer Research, 37(2), 197-206. http:/ /dx.doi.org/10.1086/651257 


\section{Appendix A: Operationalisation}

\begin{tabular}{|c|c|c|}
\hline Variable & Item & Source \\
\hline $\begin{array}{l}\text { Perceived } \\
\text { Usefulness }\end{array}$ & $\begin{array}{l}\text { Bloggers' recommendations improve my } \\
\text { shopping performance. } \\
\text { Bloggers' recommendations enhance my } \\
\text { shopping effectiveness. } \\
\text { Bloggers' recommendations increase my } \\
\text { productivity when shopping. } \\
\text { Bloggers' recommendations provide } \\
\text { useful information about the product. } \\
\text { Bloggers' recommendations are helpful } \\
\text { in understanding the product. }\end{array}$ & $\begin{array}{l}\text { Hsu, Lin and } \\
\text { Chiang (2013), } \\
\text { Park, Lee and } \\
\text { Han (2007) }\end{array}$ \\
\hline Trustworthiness & $\begin{array}{l}\text { I believe bloggers' recommendations to } \\
\text { be true. } \\
\text { I trust information on blogs to be true. } \\
\text { Bloggers are trustworthy. } \\
\text { Bloggers' recommendations are more } \\
\text { trustworthy than company sponsored } \\
\text { advertising because they are posted by } \\
\text { peers. } \\
\text { Bloggers' recommendations are reliable. } \\
\text { Recommendations posted by trustworthy } \\
\text { bloggers are to be considered true. } \\
\text { I think bloggers' recommendations are } \\
\text { convincing. } \\
\text { I think bloggers' recommendations are } \\
\text { credible. } \\
\text { I think bloggers' recommendations are } \\
\text { accurate. }\end{array}$ & $\begin{array}{l}\text { Hsu, Lin and } \\
\text { Chiang (2013), } \\
\text { Lee and Ma } \\
\text { (2012), Erkan } \\
\text { and Evans } \\
\text { (2016) }\end{array}$ \\
\hline $\begin{array}{l}\text { Information } \\
\text { Quality }\end{array}$ & $\begin{array}{l}\text { Each recommendation post of the products } \\
\text { has sufficient reasons supporting the } \\
\text { opinions. } \\
\text { Each recommendation post of the products } \\
\text { is objective. } \\
\text { Each recommendation post of the products } \\
\text { is understandable. } \\
\text { Each recommendation post of the products } \\
\text { is credible. } \\
\text { Each recommendation post of the products } \\
\text { is clear. }\end{array}$ & $\begin{array}{l}\text { Park, Lee and } \\
\text { Han (2007) }\end{array}$ \\
\hline
\end{tabular}


Appendix A: (continued)

\begin{tabular}{|c|c|c|}
\hline Variable & Item & Source \\
\hline & $\begin{array}{l}\text { In general, the quality of each recommen- } \\
\text { dation post of the products is high. }\end{array}$ & \\
\hline $\begin{array}{l}\text { Perceived } \\
\text { Benefits }\end{array}$ & $\begin{array}{l}\text { Bloggers' recommendations help me to } \\
\text { reduce risk of making a decision. } \\
\text { Bloggers' recommendations can help me } \\
\text { gain knowledge about how the product } \\
\text { works. } \\
\text { Bloggers' recommendations can help me } \\
\text { obtain product information in general. } \\
\text { Bloggers' recommendations can help me } \\
\text { judge product quality. } \\
\text { Bloggers' recommendations can help me } \\
\text { check product feature and function. } \\
\text { Bloggers' recommendations help me learn } \\
\text { about products. } \\
\text { Bloggers' recommendations may provide } \\
\text { different opinions about the product that } \\
\text { I never considered. }\end{array}$ & $\begin{array}{l}\text { Lee and Ma } \\
(2012)\end{array}$ \\
\hline $\begin{array}{l}\text { Attitude } \\
\text { towards } \\
\text { Bloggers' } \\
\text { Recommen- } \\
\text { dations }\end{array}$ & $\begin{array}{l}\text { I think following bloggers' recommen- } \\
\text { dations would be good for me. } \\
\text { I have a positive opinion about bloggers' } \\
\text { recommendations. } \\
\text { I like bloggers' recommendations. } \\
\text { Overall my attitude toward bloggers' } \\
\text { recommendations is favourable. }\end{array}$ & $\begin{array}{l}\text { Casaló, Flavian } \\
\text { and Guinaliu } \\
\text { (2011), Lee, } \\
\text { Xiong and } \\
\text { Hu (2012) }\end{array}$ \\
\hline $\begin{array}{l}\text { Purchase } \\
\text { Intention }\end{array}$ & $\begin{array}{l}\text { It is highly probable that I will choose the } \\
\text { product recommended by blogger. } \\
\text { It is very likely that I would seriously } \\
\text { consider the product recommended by } \\
\text { blogger. } \\
\text { If I were to make a decision I will certainly } \\
\text { purchase the product recommended by } \\
\text { blogger. } \\
\text { It is highly probable I would suggest } \\
\text { buying the product recommended by } \\
\text { blogger. }\end{array}$ & $\begin{array}{l}\text { Plotkina and } \\
\text { Munzel (2016) }\end{array}$ \\
\hline
\end{tabular}


